\title{
Zinc Finger Protein 1 (ZFP1) Is Involved in Trichome Initiation in Arabidopsis thaliana
}

\author{
Aidong Zhang ${ }^{1,2}$, Yihua Liu ${ }^{1}$, Chunyan Yu ${ }^{1}$, Linli Huang ${ }^{1}$, Minjie Wu ${ }^{1}$, Junyu $\mathrm{Wu}^{1}$ \\ and Yinbo Gan 1,* \\ 1 Zhejiang Key Lab of Crop Germplasm, Department of Agronomy, College of Agriculture and Biotechnology, \\ Zhejiang University, Hangzhou 310058, China; 21116035@zju.edu.cn (A.Z.); 11616003@zju.edu.cn (Y.L.); \\ 11116043@zju.edu.cn (C.Y.); 11316034@zju.edu.cn (L.H.); minjiewu@zju.edu.cn (M.W.); \\ 11516030@zju.edu.cn (J.W.) \\ 2 Shanghai Key Laboratory of Protected Horticultural Technology, Horticultural Research Institute, \\ Shanghai Academy of Agricultural Sciences, Shanghai 201403, China \\ * Correspondence: ygan@zju.edu.cn
}

Received: 17 October 2020; Accepted: 16 December 2020; Published: 18 December 2020

\begin{abstract}
Arabidopsis trichome is specialized structure that develops from epidermal cells, and is an excellent model system for studying various aspects of plant cell development and cell differentiation. Our previous studies have shown that $\mathrm{C} 2 \mathrm{H} 2$ zinc finger protein family genes, including GIS, GIS2, GIS3, ZFP5, ZFP6 and ZFP8, play an important role in controlling trichome initiation in Arabidopsis. Here, our novel results showed a $\mathrm{C} 2 \mathrm{H} 2$ zinc finger protein, ZFP1, which also plays an important role in trichome initiation in Arabidopsis. ZFP1 over-expression lines display significantly increased trichome number on cauline leaves, lateral branches and main stems in comparison with wild type plants. ZFP1 RNAi lines and loss-of-function mutants showed the opposite phenotype. Furthermore, our study also found that ZFP1 mediates the regulation of trichome initiation by cytokinin signaling. The molecular and genetic analyses reveal that ZFP1 acts upstream of key trichome initiation factors, GL3 and TRY.
\end{abstract}

Keywords: C2H2 protein; zinc finger protein 1; cytokinin; trichome; Arabidopsis thaliana

\section{Introduction}

Trichome, covering on the surface of plants' most aerial parts, could protect plants from many kinds of adverse environments [1-5]. The distribution of trichomes on abaxial and adaxial surface of rosette leaves can also be a phase marker for the vegetative growth phase. The first few rosette leaves only produce trichomes on the adaxial side. The later leaves produce trichomes on both the adaxial side and abaxial side. Based on this feature, a vegetative growth phase can be subdivided into a juvenile phase during which trichomes are only produced on the adaxial side, and an adult phase with trichomes on both sides [6].

Classic molecular and genetic analyses have identified the main regulators in Arabidopsis. They are divided into positive regulators whose mutants cover less trichomes, and negative regulators whose mutants display more or clustered trichomes [7]. In Arabidopsis, positive regulators mainly belong to three transcription factor groups, including the WD40 repeat protein [8], the R2R3 MYBs [9-11] and the basic helix-loop-helix (bHLH) factors [12,13]. They form a trimetric activator complex, which is called the MYB-bHLH-WD40 complex, and then combine with the promoter of GLABRA2 (GL2) to regulate the trichome initiation [14,15]. A group of single-repeat R3 MYBs, such as CAPRICE (CPC), TRIPTYCHON (TRY), ENHANCER OF TRY AND CPC 1(ETC1), ETC2, ETC3, TRICHOMELESS1(TCL1) and TCL2, act as the negative regulators [16-23]. They compete with R2R3 MYBs to bind to bHLH factors and 
form a repressor complex [15,24-28]. It is known that trichome development is a very complicated network regulation system. At present, two theoretical models were proposed: the activator-inhibitor model and activator-depletion model. According to activator-inhibitor model, the activators can activate their own inhibitors and up-regulate the expression of them $[29,30]$. This characteristic leads to the increase of both activators and inhibitors. The inhibitors can neutralize the activators' increase of neighbor cells. However, because of the missing evidence about activators' self-activation, this model is still in doubt. According to the activator-depletion model, TTG1 can move among young tissues and accumulate in cells. TTG1 binds to GL3 so that its movement will enhance the level of GL3. The cells with more GL3 and TTG1 will form trichomes [31].

Phytohormones play an important roles in the biological process of plant [32]. As has been reported, cytokinin stimulates the initiation of trichome in Arabidopsis [33]. With the external application of cytokinin, the trichome number in all rosette will significantly increase, but the length of these trichomes will be shorter. Cytokinin can also influence the endoreduplication of trichomes. The DNA content of plant, which is treated by cytokinin, is less than a plant that is grown under normal conditions [33].

microRNA (miRNA) consists of small endogenous, non-coding RNAs of only 20-22 nt in plants, animals and protozoa. Previous research has demonstrated that miRNA regulates trichome development by targeting SQUAMOSA PROMOTER BINDING PROTEIN LIKE (SPL) [34]. SPLs negatively regulate trichome initiation on stem and floral organ in Arabidopsis. SPL family has 17 members, and 10 of them are target genes of miRNA156 [35]. The expression level of miRNA156 is highest in young plants, and gradually decreases with the increase of plant age. In contrast, the expression level of SPLS is low in young plants, and increase with the increase of plant age. This expression mode is consistent with the phenotype of trichome in stem and floral organ. SPL9 decreases trichome initiation by targeting promoters of TCL1 and TRY [34]. UPL3/KAK mutation encoding HECT domain E3 ligase leads to an increase of trichome branches number and DNA content in nucleus. GL3 may be the target gene of UPL3 [36-38]. ETC2, an $\mathrm{m}^{6} \mathrm{~A}$ reader, controls trichome branching by affecting mRNA stability in Arabidopsis [39].

$\mathrm{C} 2 \mathrm{H} 2$ type zinc finger protein, which plays multiple functions, is one of the largest transcription factor families in Arabidopsis [40]. As shown in our previous research, GLABROUS INFLORESCENCE STEMS (GIS), GIS2, GIS3, ZINC FINGER PROTEIN 5 (ZFP5), ZFP6 and ZFP8, which all encode C2H2 zinc finger proteins, are involved in trichome initiation and root hair development, which display transcriptional hierarchy [5,41-47]. GIS3 integrates gibberellin (GA) and cytokinin signaling and GIS3 directly targets downstream genes, GIS and GIS2, to regulate trichome production [46]. ZFP6 also responds to gibberellin and cytokinin signaling and functions upstream of ZFP5 [45]. ZFP5 is involved in gibberellin signal transduction and acts upstream of ZFP8 [43,44]. All of them play key roles upstream of the trichome initiation complex MYB-bHLH-WD40. Hair $(\mathrm{H})$, which encodes a C2H2 zinc finger protein, regulates multicellular trichome formation in tomato [48]. Recently, Han et al. found that AtZP1, which belongs to $\mathrm{C} 2 \mathrm{H} 2$-type zinc finger protein family, negatively regulates root hair initiation and elongation. AtZP1 acts downstream of GL2 and regulates root hair initiation by targeting RHD6, RSL4 and RSL2 transcription [49]. Here, we cloned a C2H2 zinc finger protein ZFP1 (At1g80730), which is a homologous gene of ZFP5. Previous researchers have found that ZFP1 is a unique gene in the Arabidopsis genome [50] and is expressed at high levels in the shoot apex of seedling grown under a grow light [51]. It may participate in shoot development and acts downstream of photomorphogenic activation [51]. In our research, we found that ZFP1 also plays a role in controlling trichome initiation in Arabidopsis.

\section{Materials and Methods}

\subsection{Plant Material and Growth Conditions}

Ecotype Columbia (Col-0), the wild type Arabidopsis (Arabidopsis thaliana), was used as a control of experiments in this research. Plants were grown in a growth chamber with $20{ }^{\circ} \mathrm{C}$ to $22{ }^{\circ} \mathrm{C}, 95$ to 
$118 \mu \mathrm{mol} \mathrm{m}{ }^{-2} \mathrm{sec}^{-1}, 16 \mathrm{~h}$ light/ $8 \mathrm{~h}$ dark and $70 \%$ to $80 \%$ relative humidity. Arabidopsis seeds were sterilized with $5 \%(V / V) \mathrm{NaClO}$ for $8 \mathrm{~min}$ and washed five times with sterile distilled water in laminar flow cabinet. The sterile seeds were transferred on Murashige and Skoog (MS) mediums and incubated at $4{ }^{\circ} \mathrm{C}$ for 3 days in darkness. Then, the MS mediums were placed in a growth chamber with growth conditions as described above. Trichome numbers were counted as previously described [41,42].

\subsection{Isolation of $z f p 1$ Loss-of-Function Mutant}

$z f p 1$ seeds with T-DNA insertion in the ZFP1 promoter region were ordered from Nottingham Arabidopsis Stock Centre (NASC; catalogue number N669417). Homozygous mutants were selected with kanamycin $\left(50 \mathrm{mg} \mathrm{L}^{-1}\right)$ by testing their progenies' resistance. The presence of T-DNA insertion was confirmed by PCR with gene-specific primers (Table 1).

Table 1. Primers used for construct cloning, mutant identification and quantitative real-time PCR.

\begin{tabular}{|c|c|c|c|}
\hline Code & Sequence & Use & Reference \\
\hline ZFP1-FP & 5'-GCCGTCGACCAATTCTTTTACTTTCATTCTCTTT-3' & \multirow{2}{*}{ ZFP1 cloning } & \\
\hline ZFP1-RP & 5'-AATGCGGCCGCAGTACAACTTGATCATTAGTGAAAC-3' & & \\
\hline ZFP1-Ri-LP & 5'-GTCGACCCTCCTTGCCTTCTTCA-3' & \multirow[b]{2}{*}{ RNAi } & \\
\hline ZFP1-Ri-RP & 5'-GCGGCCGCCTATGGTCGGTTTCTGGT-3' & & \\
\hline$z f p 1-\mathrm{LP}$ & 5'-TTTATGAGCGTTTTGGTGACC-3' & \multirow{3}{*}{$\begin{array}{l}\text { mutant specific } \\
\text { primers }\end{array}$} & \\
\hline$z f p 1-R P$ & 5'-TCAATGGTGCATATATGATTTGG-3' & & \\
\hline$L B b 1.3$ & 5'-ATTTTGCCGATTTCGGAAC-3' & & \\
\hline UBQ10-RT-LP & 5'-GGTTCGTACCTTTGTCCAAGCA-3' & \multirow{2}{*}{ qRT-PCR } & \multirow{4}{*}{ [40] } \\
\hline UBQ10-RT-RP & $5^{\prime}$-CCTTCGTTAAACCAAGCTCAGTATC-3' & & \\
\hline ZFP1-RT-LP & 5'-GCGGTCACCAAAACGCTCATA-3' & \multirow{2}{*}{ qRT-PCR } & \\
\hline ZFP1-RT-RP & 5'-GAATCTGCTGACTGAACCGTGG-3' & & \\
\hline GL3-RT-LP & 5'-GAATCTGCTGACTGAACCGTGG-3' & \multirow{2}{*}{ qRT-PCR } & \multirow{2}{*}{ [40] } \\
\hline GL3-RT-RP & 5'-CAAGAACGTTGTCGATGTGATAATC-3' & & \\
\hline TRY-RT-LP & 5'-TTGTCGGTGATAGGTGGGATTT-3' & \multirow{2}{*}{ qRT-PCR } & \multirow{2}{*}{ [2] } \\
\hline TRY-RT-RP & 5'-ACGGTGAGGCTTGGTATGTTTG-3' & & \\
\hline ARR5-RT-LP & 5'-TTGCGTCCCGAGATGTTAGAT-3' & \multirow{2}{*}{ qRT-PCR } & \multirow{2}{*}{ [40] } \\
\hline ARR5-RT-RP & 5'-TGAGTAACCGCTCGATGAACTTC-3' & & \\
\hline
\end{tabular}

\subsection{Construct Cloning}

For overexpression and RNAi constructs, the fragments were amplified by PCR from cDNA of Col-0 using PrimeSTAR HS DNA polymerase (TaKaRa Bio Inc., Kusatsu, Japan) and inserted into a pENTR-1A vector (Invitrogen, Calsbad, CA, USA). Then, the fragments recombined into destination vectors with Gateway LR reaction (Invitrogen). The destination vectors were obtained from VIB (Flanders Interuniversity Institute for Biotechnology) as described before [43,45]. The constructs were finally transferred into Agrobacterium tumefaciens Stain GV3101 and transformed Arabidopsis by floral-dip method as described by Clough and Bent (1998) [52]. The primers used for cloning are list in Table 1.

\subsection{Cytokinin Treatment and Gene Expression Analyses}

For external cytokinin treatment, 6-benzylaminopurine (6BA, Sigma-Aldrich Corp., St. Louis, MO, USA) was used in this study as we described before [42,43,45]. Plants were sprayed with $100 \mu \mathrm{mol} \mathrm{L}-1$ 6BA and took samples after $2 \mathrm{~h}$ for RNA extraction when their inflorescence shoots reached 2 to $3 \mathrm{~cm}$. For trichome phenotype analyses, plants were grown on soil until three to four leaves had emerged and sprayed twice a week with different concentrations of 6BA or mock solution until plants were ready for analyses as described previously [42,45]. 


\subsection{RNA Extraction and Real-Time PCR}

Total RNA was isolated with Trizol reagent (Invitrogen). Two $\mu g$ of total RNA was reversely transcribed to cDNA with M-MLV transcriptase (Promega, Madison, WI, USA) as described in their instruction. The cDNA was diluted four times for real-time PCR. Real-time PCR was performed with SYBR Green PCR mix (Takara). The results of subtraction, which consisted of subtracting the Ct value of UBQ10 (At4g05320) from the Ct value of the target genes, are represented by sign $\Delta \mathrm{Ct}$. The relative expression of the target genes was obtained by calculating $2^{-\Delta \mathrm{Ct}}$ as previously described [46]. The primers used in this study are listed in Table 1.

\subsection{Bioinformatic Analyses}

The coding sequence (CDS) and protein sequences were acquired from Tair (https://www. arabidopsis.org/). ClustalW (https://www.genome.jp/tools-bin/clustalw) was used for CDS and protein sequences alignment. Jalview software [53] was used for the alignments edit. The protein domain was predicted by SMART (https://smart.embl-heidelberg.de/).

\subsection{Statistical Analyses}

All data displaying in figures were analyzed by means of ANOVA. SPSS software, version 14.0 (SPSS Inc., Chicago, IL, USA), was used for the significance analysis. Student's t-test was calculated at either $5 \%\left({ }^{*}, p<0.05\right)$ or $1 \%\left({ }^{* *}, p<0.01\right)$ probability to evaluate the difference as described before [54].

\section{Results}

\subsection{Loss of Function of ZFP1 Affects Trichome Initiation}

As our previous results showed that ZFP5 plays a key role in regulating trichome initiation in Arabidopsis, we are very curious whether its homologous gene $Z F P 1$ plays a similar role in trichome development. ZFP1, with 687 bp open reading frames encoding 228 amino acids, showed high homologous with other $\mathrm{C} 2 \mathrm{H} 2$ zinc finger protein genes (Figure S1) [49]. We ordered $z f p 1$ mutant (catalog No. N669417) from the Nottingham Arabidopsis Stock Centre (NASC). zfp1 carries a T-DNA insertion in the ZFP1 promoter region and was verified by genomic PCR. We also constructed an RNAi vector, which silenced the expression of ZFP1. We transferred this vector to Col-0 plants (wild type, WT) and selected ZFP1-Ri-6 line for phenotypic observation (Figure 1). To assess the function of ZFP1 in regulating trichome initiation, we counted the trichome numbers of WT, zfp1 and ZFP1-Ri-6 on their branches, cauline leaves, stem, and sepals. As shown in Figure 2A-C and Figure S2, the mutant and RNAi lines had significantly fewer trichomes than that of WT. These results indicate that ZFP1 may involve in trichome initiation in Arabidopsis.

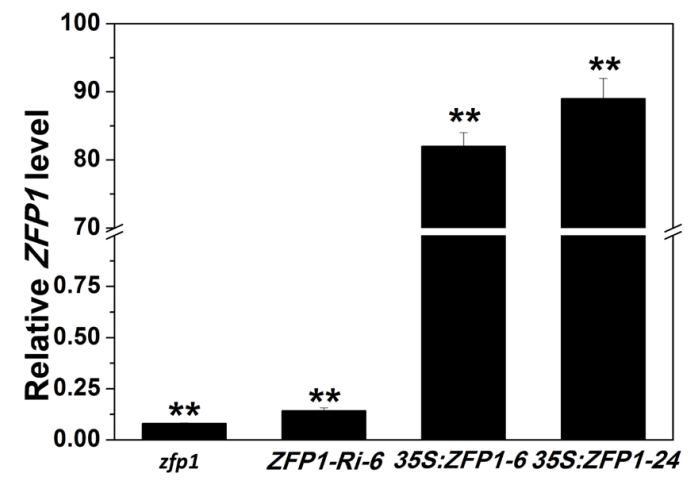

Figure 1. The relative expression level of ZFP1 in $z f p 1, Z F P 1-R i-6$ and 35S:ZFP1 lines. The values of $U B Q 10$ were used as control to normalize the expression of target genes. Error bars indicate standard error. ${ }^{* *} p<0.01$. 

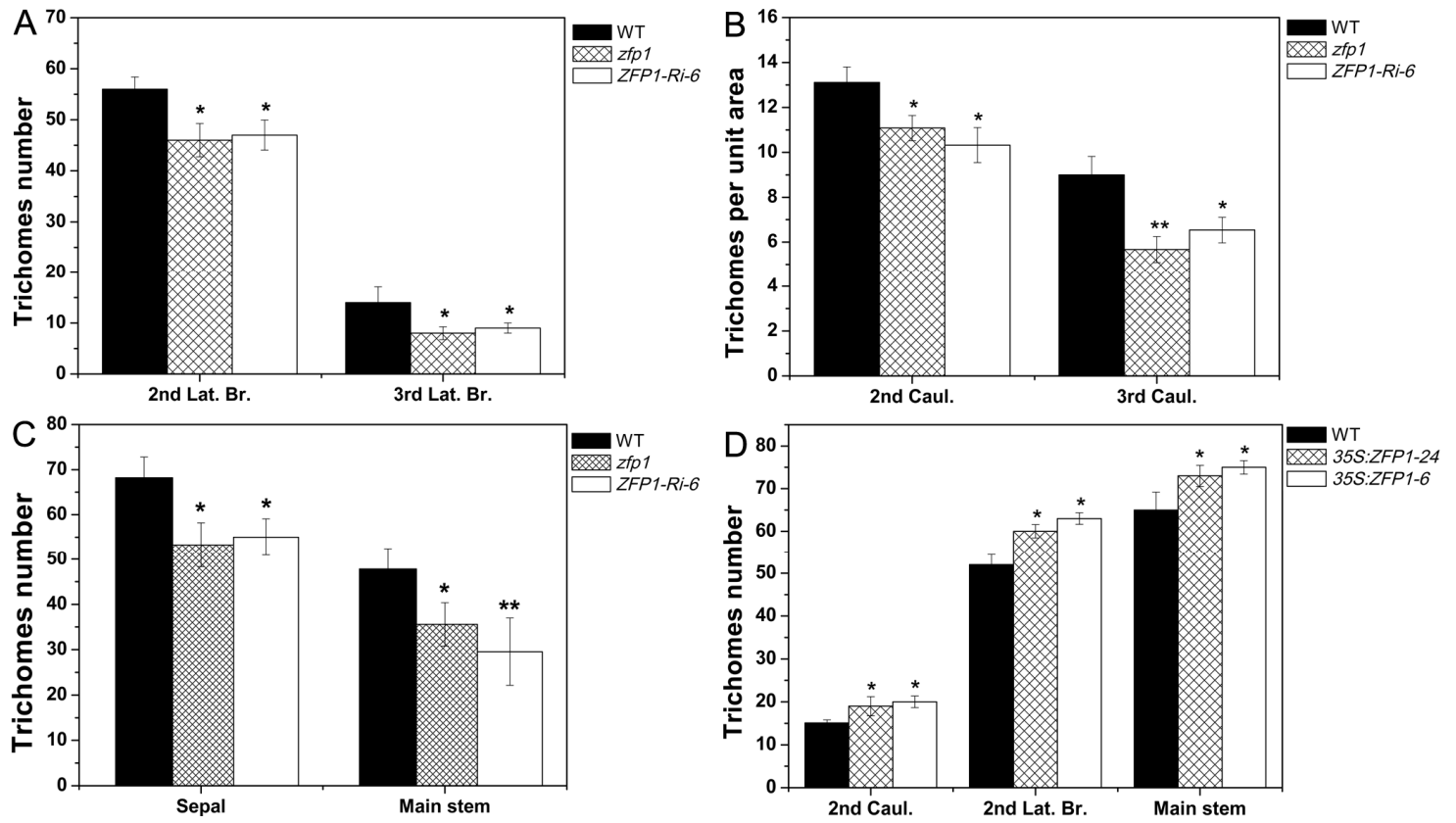

Figure 2. Trichome number on different organs in wild type, zfp1 mutant, ZFP1-Ri-6 and 35S:ZFP1 lines. Trichomes number on the second and third branches (A), the second and third cauline leaves (B), sepals and main stems, (C) in wild type, zfp1 mutant and ZFP1-Ri-6 line. (D) Trichomes number in wild type and 35S:ZFP1 lines. Trichomes number was the average number of counting at least 20 plants.

Error bars indicate the standard error. ${ }^{*} p<0.05$; and ${ }^{* *} p<0.01$.

\subsection{Overexpression of ZFP1 Stimulates Trichome Initiation}

To further confirm our hypothesis, we created 35S:ZFP1 transgenic lines and chose two representative overexpression lines (35S:ZFP1-6 and 35S:ZFP1-24) (Figure 1). Both lines displayed significantly higher trichomes density on second branches, second cauline leaves and stems than WT plants (Figure 2D). These results further confirm that ZFP1 positively controls trichome initiation in Arabidopsis.

\subsection{ZFP1 Is Required for Cytokinin Signal to Control Trichome Initiation during Inflorescence Development}

Our previous study showed that $\mathrm{C} 2 \mathrm{H} 2$ ZINC FINGER PROTEIN could regulate trichome initiation through cytokinin signaling [42,45]. To investigate whether ZFP1 plays a similar role in regulating trichome initiation through cytokinin signaling, WT plants were sprayed with 6BA and then sampled after $2 \mathrm{~h}$ to test the expression level of ZFP1. As shown in Figure 3, the strong induction of a primary cytokinin response gene ARR 5 after $6 \mathrm{BA}$ treatment indicates that the effectiveness of cytokinin application signaling. The relative expression of ZFP1 was also significantly up-regulated by 6BA treatment.

To further confirm the role of cytokinin, $z f p 1$ mutant and wild type plants were treated with $10 \mu \mathrm{M}$ and $100 \mu \mathrm{M}$ 6BA. Then, we counted the trichome numbers. As shown in Figure 4, the trichome numbers increase in $z f p 1$ plants with 6BA application, which shows a less sensitive phenotype than that of wild type plants on the second branches, second cauline leaves, and third cauline leaves. Taken together, these data indicate that ZFP1 is required for the cytokinin signal in controlling the trichome initiation in Arabidopsis. 


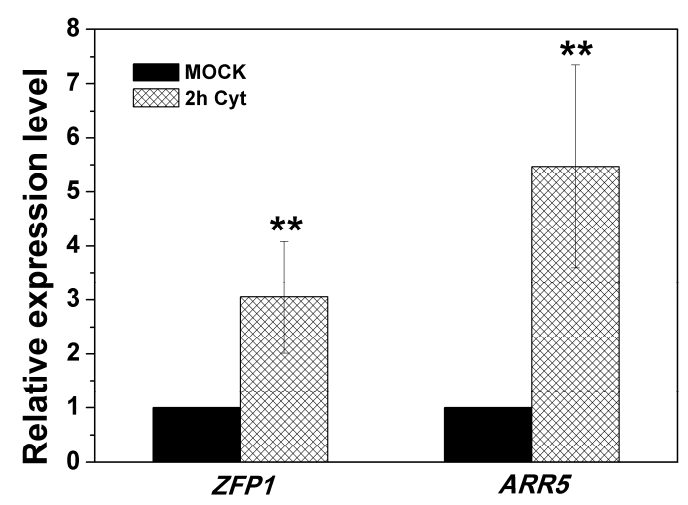

Figure 3. ZFP1 expression level in wild type when treated with $100 \mu \mathrm{M} 6 \mathrm{BA}$. The values were normalized against the levels of $U B Q 10$ as a control. Error bars indicate standard error. ${ }^{* *} p<0.01$.
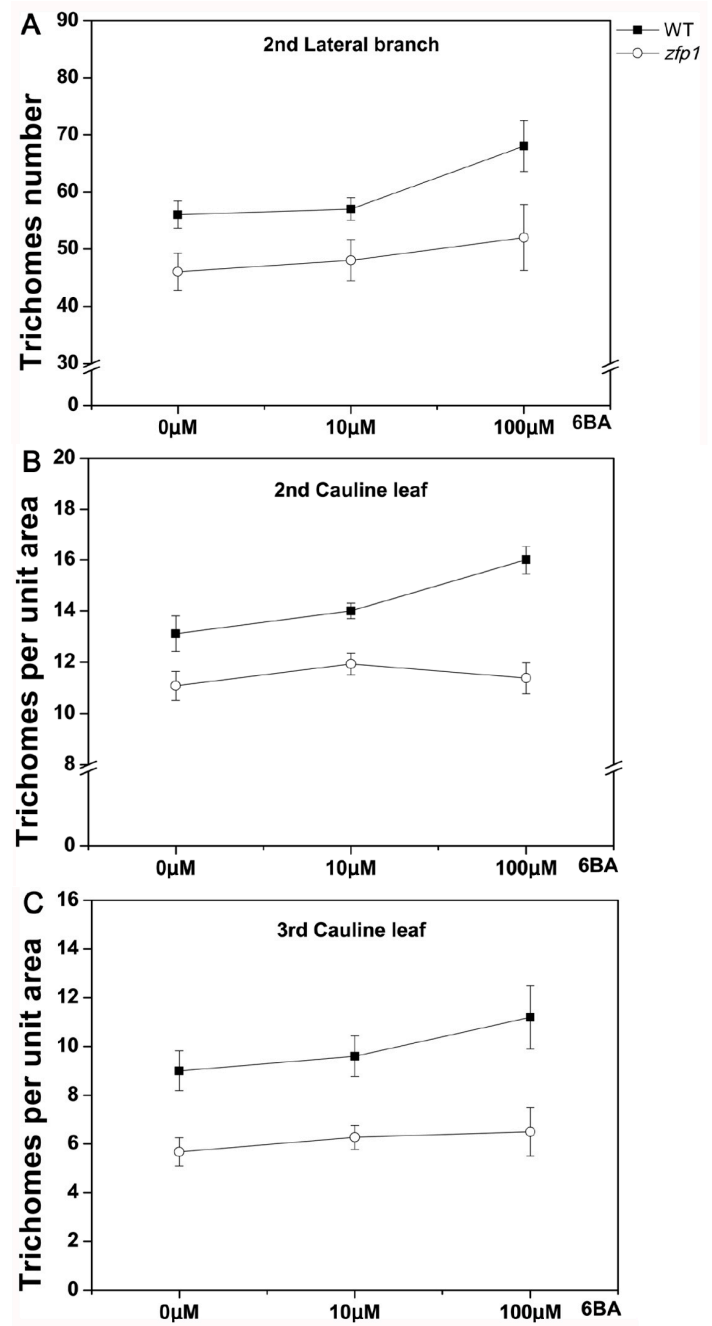

Figure 4. Wild type and zfp1 mutant. Response to 6BA treatment. Trichomes number on the second lateral branches (A), second (B) and third cauline leaves (C) in wild type and zfp1 mutant when treated with different concentrations of 6BA. The trichomes number was the average number of at least 20 plants. Error bars indicate the standard error.

\subsection{ZFP1 Acts Upstream of Trichome Initiation Complex}

Trichome initiation is mainly regulated by MYB-bHLH-WD40 complex. To verify if ZFP1 regulates trichome initiation by this pathway, we analyzed the relative expression level of GL3 and TRY. 
Our results showed that the expression level of GL3 in mutant and RNAi line was significantly decreased in comparison to the wild type. The expression level of negative regulator TRY was increased in mutant and RNAi line compared with wild type. In contrast, in the ZFP1 overexpression line, the expression level of GL3 was up-regulated and TRY was down-regulated compared to that of wild type (Figure 5). These results suggest indicate that ZFP1 acts upstream of the trichome initiation complex.

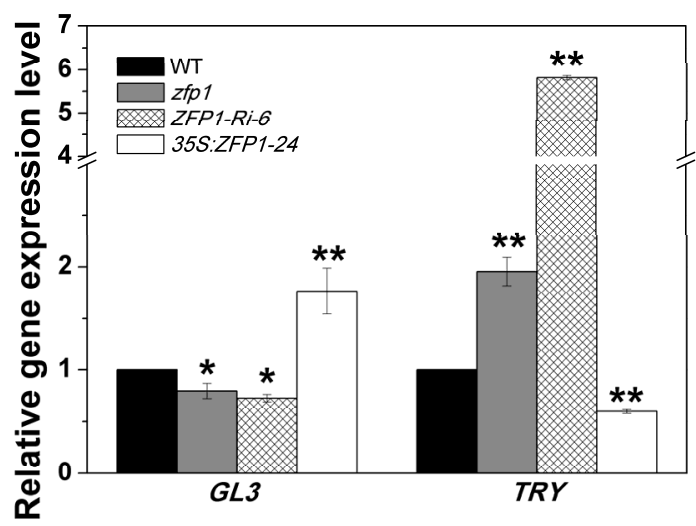

Figure 5. Relative expression level of GL3 and TRY in wild type, zfp1 mutant and ZFP1 overexpression line. The values were normalized against the levels of $U B Q 10$ as a control. Error bars indicate the standard error. ${ }^{*} p<0.05$; and ${ }^{* *} p<0.01$.

To further confirm this result, we over-expressed ZFP1 gene in gl3 mutant and detected if glabrous phenotype of $g l 3$ could be restored by over-expression of ZFP1. As shown in Figure 6, 35S:ZFP1:gl3 did not rescue $g l 3$ mutant's phenotype. These data further support the hypothesis that ZFP1 acts upstream of trichome initiation complex.
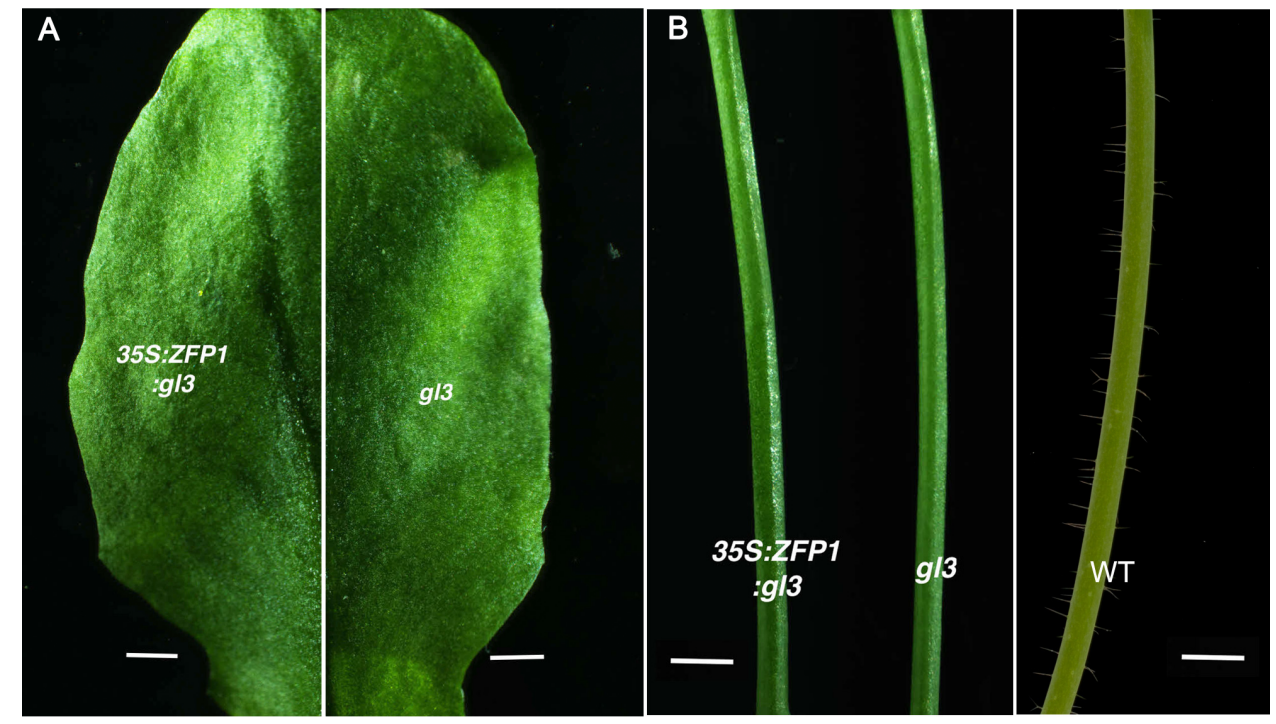

Figure 6. Genetic interaction between ZFP1 and GL3 gene. (A) Trichome initiation on the rosette leaf of 35S:ZFP1:gl3 and gl3. (B) Trichome initiation on stem of 35S:ZFP1:gl3, gl3, and wild type. Bars = $2 \mathrm{~mm}$.

\subsection{The Expression Patterns of ZFP1}

Sequence analysis displayed that $Z F P 1$ contains a $\mathrm{C} 2 \mathrm{H} 2$ conserved domain, which is found in all $\mathrm{C} 2 \mathrm{H} 2$ zinc finger protein family (Figure S1). To analyze the expression pattern of ZFP1, we checked its expression level in different organs. Quantitative RT-PCR data showed that ZFP1 was mainly expressed in flower, main stem, silique and root but was expressed at lower levels in other organs 
(Figure 7). These results were similar with ZFP1 expression profiles extracted from Arabidopsis databases (eFP Brower, http://bar.utoronto.ca/efp_arabidopsis/cgi-bin/efpWeb.cgi) (Figure S3).

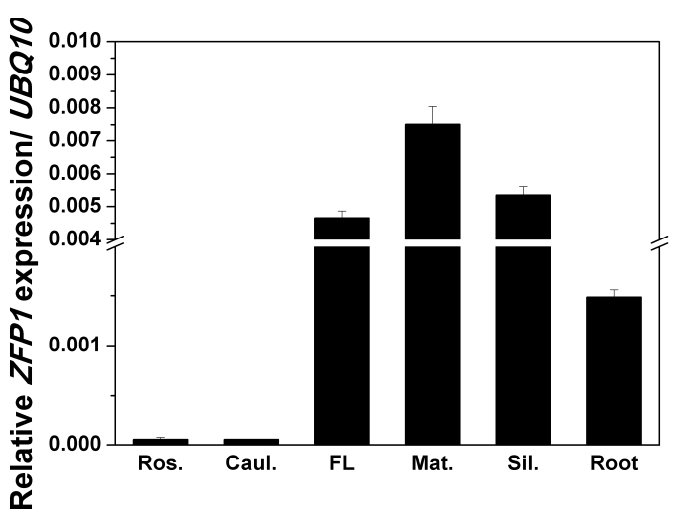

Figure 7. Analysis of ZFP1 expression in different tissues of wild type. Ros., rosette leaf; Caul., cauline leaf; FL, flower; Mat., main stem; Sil., silique; Root, Root. The values were normalized against the levels of $U B Q 10$ as a control.

\section{Discussion}

Our previous results have shown that $\mathrm{C} 2 \mathrm{H} 2$ type zinc finger protein family members, GIS, GIS2 and ZFP8, could control the trichome development in Arabidopsis, but their responses to hormonal signals are diverse $[41,42,55]$. GIS plays a main role in controlling the initiation on branches and GIS2 regulates the number of trichomes on flowers, while ZFP8 regulates trichomes development on cauline leaves. As shown in Figure 2, ZFP1 also plays a predominant role in branches' trichome initiation.

Cytokinin plays a positive role in trichome initiation in Arabidopsis. The expression level of GL1, GL3, EGL3 and MYB23 is significantly induced after cytokinin application. In this study, 6BA significantly induced the expression of ZFP1 and $z f p 1$ mutant plants were shown to be less sensitive to cytokinin than that of wild type (Figures 3 and 4). At the same time, ZFP1 acts upstream of trichome initiation complex gene GL3 that is induced by cytokinin, which means ZFP1 may respond to cytokinin signaling by GL3. These results suggest that exogenous cytokinin induces the expression of ZFP1, which increases the expression of GL3 and eventually promotes trichome initiation in Arabidopsis (Figure 8). It is well-known that gibberellin participates in many growth and development processes, including seed germination, hypocotyl elongation, flowering and trichome development. GA biosynthesis mutant ga1-3 displays glabrous on leaves, and phenotypes are recovered by applying GA [56]. With the treatment of GA, the expression level of GL1, MYB23, GL3 and EGL2 is significantly increased, while the expression of TRY, ETC1 and ETC2 is significantly decreased [33]. In addition, ZFP5 responds to gibberellin and acts upstream of GIS, GIS2, ZFP8 and the trichome initiation complex [38]. Our previous study also demonstrated that ZFP6 and GIS3 could control trichome development by integrating gibberellin and cytokinin signal $[45,46]$. However, whether ZFP1 plays any role in control trichome development through GA signal is still unknown and needs to be further investigated.

Trichomes are specialized epidermal cells, protecting plants from abiotic and biotic stresses [43]. Our previous studies have found that ZINC FINGER PROTEIN 3 (ZFP3) participates in the responses of salt stress and osmotic stress by influencing the expression of stress-related genes and changing the proline accumulation and chlorophyll content in Arabidopsis [55]. Constitutive expression of ZFP3 enhances the tolerance of Arabidopsis to salt and osmatic stress. zfp3 loss-of-function mutants were shown to be more sensitive to salt and osmotic stress. With regards to ZFP3's homologous gene, whether ZFP1 is also involved in abiotic stresses needs to be explored in the future. 


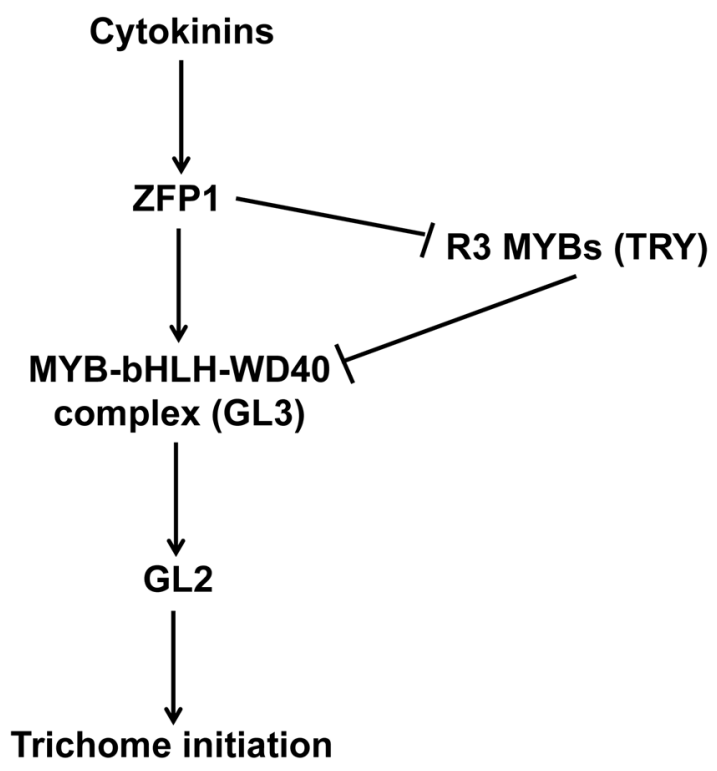

Figure 8. Model of the ZFP1 in regulating trichome initiation in response to cytokinin in Arabidopsis.

\section{Conclusions}

Our results suggest that ZFP1 plays a positive role in regulating trichome initiation by acting upstream of key trichome initiation factors, GL3 and TRY, in Arabidopsis through the cytokinin pathway.

Supplementary Materials: The following are available online at http:/www.mdpi.com/2077-0472/10/12/645/s1, Figure S1: Alignment of CDS sequences (A) and protein sequences (B) of ZFP1, ZFP2, ZFP3, ZFP4, ZFP5, and ZFP7 in Arabidopsis, Figure S2: Phenotype of $z f p 1$ mutant, WT, and 35S:ZFP1. (A) Phenotype of $z f p 1$ mutant, WT, and 35S:ZFP1 on sepal. (B) Phenotype of $z f p 1$ mutant, WT, and 35S:ZFP1 on stem, Figure S3: Expression profiles of ZFP1 in database of public microarray data.

Author Contributions: Methodology, A.Z. and Y.G.; validation, A.Z., C.Y. and Y.L.; formal analysis, L.H. and M.W.; resources, Y.G.; data curation, A.Z. and J.W.; writing-original draft preparation, A.Z. and Y.G.; funding acquisition, Y.G. All authors have read and agreed to the published version of the manuscript.

Funding: This research was funded by the National Natural Science Foundation of China (Grant number: 31570183; 31529001; 31661143004) and the National Key R \& D Program of China (grand number: 2016YFD0100701).

Acknowledgments: We thank Ali Raza Khan from Zhejiang University for critical reading our manuscript and Z.Y. Qi from the Agricultural Experiment Station, Zhejiang University for his assistance during the experiment.

Conflicts of Interest: The authors declare no conflict of interest. The funders had no role in the design of the study; in the collection, analyses or interpretation of data; in the writing of the manuscript, or in the decision to publish the results.

\section{References}

1. Hauser, M.T. Molecular basis of natural variation and environmental control of trichome patterning. Front. Plant Sci. 2014, 5, 320. [CrossRef]

2. Xue, X.Y.; Zhao, B.; Chao, L.M.; Chen, D.Y.; Cui, W.R.; Mao, Y.B.; Wang, L.J.; Chen, X.Y. Interaction between Two Timing MicroRNAs Controls Trichome Distribution in Arabidopsis. PLoS Genet. 2014, 10, e1004266. [CrossRef] [PubMed]

3. Koudounas, K.; Manioudaki, M.E.; Kourti, A.; Banilas, G.; Hatzopoulos, P. Transcriptional profiling unravels potential metabolic activities of the olive leaf non-glandular trichome. Front. Plant Sci. 2015, 6, 633. [CrossRef] [PubMed]

4. Stefanowicz, K.; Lannoo, N.; Zhao, Y.; Eggermont, L.; Van Hove, J.; Al Atalah, B.; Van Damme, E.J. Glycan-binding F-box protein from Arabidopsis thaliana protecs plants from Pseudomonas syringae infection. BMC Plant Biol. 2016, 16, 213. [CrossRef] [PubMed] 
5. Liu, Y.; Liu, D.; Khan, A.R.; Liu, B.; Wu, M.; Huang, L.; Wu, J.; Song, G.; Ni, H.; Ying, H.; et al. NbGIS regulates glandular trichome initiation through GA signaling in tobacco. Plant Mol. Biol. 2018, 98, 153-167. [CrossRef] [PubMed]

6. Telfer, A.; Bollman, K.M.; Poethig, R.S. Phase change and the regulation of trichome distribution in Arabidopsis thaliana. Development 1997, 124, 645-654.

7. Balkunde, R.; Pesch, M.; Hülskamp, M. Trichome patterning in Arabidopsis thaliana: From genetic to molecular models. Curr. Top. Dev. Biol. 2010, 91, 299-321. [CrossRef]

8. Walker, A.R.; Davison, P.A.; Bolognesi-Winfield, A.C.; James, C.M.; Srini-vasan, N.; Blundell, T.L.; Esch, J.J.; Marks, M.D.; Gray, J.C. The TRANSPARENT TESTA GLABRA 1 locus, which regulates trichome differentiation and anthocyanin biosynthesis in Arabidopsis, encodes a WD40 repeat protein. Plant Cell 1999, 11, 1337-1350. [CrossRef]

9. Kirik, V.; Lee, M.M.; Wester, K.; Herrmann, U.; Zheng, Z.; Oppenheimer, D.; Schiefelbein, J.; Hülskamp, M. Functional diversification of MYB23 and GL1 genes in trichome morphogenesis and initiation. Development 2005, 132, 1477-1485. [CrossRef]

10. Song, F.L.; Milliken, O.N.; Pham, H.; Seyit, R.; Napoli, R.; Preston, J.; Koltunow, A.M.; Parish, R.W. The Arabidopsis MYB5 transcription factor regulates mucilage synthesis, seed coat development, and trichome morphogenesis. Plant Cell 2009, 21, 72-89. [CrossRef]

11. Tominaga-Wada, R.; Nukumizu, Y.; Sato, S.; Kato, T.; Tabata, S.; Wada, T. Functional divergence of MYB-related genes, WEREWOLF and AtMYB23 in Arabidopsis. Biosci. Biotechnol. Biochem. 2012, 76, 883-887. [CrossRef] [PubMed]

12. Payne, C.T.; Zhang, F.; Lloyd, A.M. GL3 encodes a bHLH protein that regulates trichome development in Arabidopsis through interaction with GL1 and TTG1. Genetics 2000, 156, 1349-1362. [PubMed]

13. Zhang, F.; Gonzalez, A.; Zhao, M.; Payne, C.T.; Lloyd, A. A network of redundant bHLH proteins functions in all TTG1-dependent pathways of Arabidopsis. Development 2003, 130, 4859-4869. [CrossRef] [PubMed]

14. Rerie, W.G.; Feldmann, K.A.; Marks, M.D. The GLABRA2 gene encodes a homeo domain protein required for normal trichome development in Arabidopsis. Genes. Dev. 1994, 8, 1388-1399. [CrossRef]

15. Ishida, T.; Kurata, T.; Okada, K.; Wada, T. A genetic regulatory network in the development of trichomes and root hairs. Annu. Rev. Plant Biol. 2008, 59, 365-386. [CrossRef]

16. Wada, T.; Tachibana, T.; Shimura, Y.; Okada, K. Epidermal cell differentiation in Arabidopsis determined by a Myb homolog, CPC. Science 1997, 277, 1113-1116. [CrossRef]

17. Schellmann, S.; Schnittger, A.; Kirik, V.; Wada, T.; Okada, K.; Beermann, A.; Thumfahrt, J.; Jürgens, G.; Hülskamp, M. TRIPTYCHON and CAPRICE mediate lateral inhibition during trichome and root hair patterning in Arabidopsis. EMBO J. 2002, 21, 5036-5046. [CrossRef]

18. Esch, J.J.; Chen, M.A.; Hillestad, M.; Marks, M.D. Comparison of TRY and the closely related At1g01380 gene in controlling Arabidopsis trichome patterning. Plant J. 2004, 40, 860-869. [CrossRef]

19. Kirik, V.; Simon, M.; Huelskamp, M.; Schiefelbein, J. The ENHANCER OF TRY AND CPC1 gene acts redundantly with TRIPTYCHON and CAPRICE in trichome and root hair cell patterning in Arabidopsis. Dev. Bio. 2004, 268, 506-513. [CrossRef] [PubMed]

20. Simon, M.; Lee, M.M.; Lin, Y.; Gish, L.; Schiefelbein, J. Distinct and overlapping roles of single-repeat MYB genes in root epidermal patterning. Dev. Biol. 2007, 311, 566-578. [CrossRef]

21. Wang, S.; Kwak, S.H.; Zeng, Q.; Ellis, B.E.; Chen, X.Y.; Schiefelbein, J.; Chen, J.G. TRICHOMELESS1 regulates trichome patterning by suppressing GLABRA1 in Arabidopsis. Development 2007, 134, 3873-3882. [CrossRef] [PubMed]

22. Gan, L.; Xia, K.; Chen, J.G.; Wang, S. Functional characterization of TRICHOMELESS2, a new single-repeat R3 MYB transcription factor in the regulation of trichome patterning in Arabidopsis. BMC Plant Biol. 2011, 11, 176. [CrossRef] [PubMed]

23. Tominaga-Wada, R.; Nukumizu, Y. Expression Analysis of an R3-Type MYB Transcription Factor CPC-LIKE MYB4 (TRICHOMELESS2) and CPL4-Related Transcripts in Arabidopsis. Int. J. Mol. Sci. 2012, 13, 3478-3491. [CrossRef] [PubMed]

24. Wester, K.; Digiuni, S.; Geier, F.; Timmer, J.; Fleck, C.; Hülskamp, M. Functional diversity of R3 single-repeat genes in trichome development. Development 2009, 136, 1487-1496. [CrossRef]

25. Edgar, B.A.; Zielke, N.; Gutierrez, C. Endocycles: A recurrent evolutionary innovation for post-mitotic cell growth. Nat. Rev. Mol. Cell Biol. 2014, 15, 197-210. [CrossRef] 
26. Wang, S.; Chen, J.G. Regulation of cell fate determination by single-repeat R3 MYB transcription factors in Arabidopsis. Front. Plant Sci. 2014, 5, 133. [CrossRef]

27. Vadde, B.V.L.; Challa, K.R.; Nath, U. The TCP4 transcription factor regulates trichome cell differentiation by directly activating GLABROUS INFLORESCENCE STEMS in Arabidopsis thaliana. Plant J. 2018, 93, 259-269. [CrossRef] [PubMed]

28. Wen, J.; Li, Y.; Qi, T.; Gao, H.; Liu, B.; Zhang, M.; Huang, H.; Song, S. The C-terminal domains of Arabidopsis GL3/EGL3/TT8 interact with JAZ proteins and mediate dimeric interactions. Plant Signal. Behav. 2018, 13, e1422460. [CrossRef]

29. Pesch, M.; Hülskamp, M. Creating a two-dimensional pattern de novo during Arabidopsis trichome and root hair initiation. Curr. Opin. Genet. Dev. 2004, 14, 422-427. [CrossRef] [PubMed]

30. Hülskamp, M. Plant trichomes: A model for cell differentiation. Nat. Rev. Mol. Cell. Biol. 2004, 5, 471-480. [CrossRef]

31. Pesch, M.; Hülskamp, M. One, two, three ... models for trichome patterning in Arabidopsis? Curr. Opin. Plant Biol. 2009, 12, 587-592. [CrossRef]

32. Pattanaik, S.; Patra, B.; Singh, S.K.; Yuan, L. An overview of the gene regulatory network controlling trichome development in the model plant, Arabidopsis. Front. Plant Sci. 2014, 5, 259. [CrossRef]

33. Maes, L.; Inze, D.; Goossens, A. Functional specialization of the TRANSPARENT TESTA GLABRA1 network allows differential hormonal control of laminal and marginal trichome initiation in Arabidopsis rosette leaves. Plant Physiol. 2008, 148, 1453-1464. [CrossRef]

34. Yu, N.; Cai, W.; Wang, S.; Shan, C.; Wang, L.; Chen, X. Temporal control of trichome distribution by microRNA156-targeted SPL genes in Arabidopsis thaliana. Plant Cell 2010, 22, 2322-2335. [CrossRef]

35. Rhoades, M.W.; Reinhart, B.J.; Lim, L.P.; Burge, C.B.; Bartel, B.; Bartel, D.P. Prediction of plant microRNA targets. Cell 2002, 110, 513-520. [CrossRef]

36. Downes, B.P.; Stupar, R.M.; Gingerich, D.J.; Vierstra, R.D. The HECT ubiquitin-protein ligase (UPL) family in Arabidopsis: UPL3 has a specific role in trichome development. Plant J. 2003, 35, 729-742. [CrossRef]

37. El Refy, A.; Perazza, D.; Zekraoui, L.; Valay, J.G.; Bechtold, N.; Brown, S.; Hülskamp, M.; Herzog, M.; Bonneville, J.M. The Arabidopsis KAKTUS gene encodes a HECT protein and controls the number of endoreduplication cycles. Mol. Genet. Genom. 2003, 270, 403-414. [CrossRef]

38. Sako, K.; Maki, Y.; Imai, K.K.; Aoyama, T.; Goto, D.B.; Yamaguchi, J. Control of endoreduplication of trichome by RPT2a, a subunit of the $19 \mathrm{~S}$ proteasome in Arabidopsis. J. Plant Res. 2010, 123, 701-706. [CrossRef]

39. Wei, L.; Song, P.; Wang, Y.; Lu, Z.; Tang, Q.; Yu, Q.; Xiao, Y.; Zhang, X.; Duan, H.; Jia, G. The m ${ }^{6}$ A Reader ECT2 Controls Trichome Morphology by Affecting mRNA Stability in Arabidopsis. Plant Cell 2018, 30, 968-985. [CrossRef]

40. Zang, D.; Wang, C.; Ji, X.; Wang, Y. Tamarix hispida zinc finger protein ThZFP1 participates in salt and osmotic stress tolerance by increasing proline content and SOD and POD activities. Plant Sci. 2015, 235, 111-121. [CrossRef]

41. Gan, Y.; Kumimoto, R.; Liu, C.; Ratcliffe, O.; Yu, H.; Broun, P. GLABROUS INFLORESCENCE STEMS modulates the regulation by gibberellins of epidermal differentiation and shoot maturation in Arabidopsis. Plant Cell 2006, 18, 1383-1395. [CrossRef] [PubMed]

42. Gan, Y.; Liu, C.; Yu, H.; Broun, P. Integration of cytokinin and gibberellin signalling by Arabidopsis transcription factors GIS, ZFP8 and GIS2 in the regulations of epidermal cell fate. Development 2007, 134, 2073-2081. [CrossRef] [PubMed]

43. Zhou, Z.; An, L.; Sun, L.; Zhu, S.; Xi, W.; Broun, P.; Yu, H.; Gan, Y. Zinc Finger Protein5 is required for the control of trichome initiation by acting upstream of Zinc Finger Protein8 in Arabidopsis. Plant Physiol. 2011, 157, 673-682. [CrossRef] [PubMed]

44. Zhou, Z.; An, L.; Sun, L.; Gan, Y. ZFP5 encodes a functionally equivalent GIS protein to control trichome initiation. Plant Signal. Behav. 2012, 7, 28-30. [CrossRef]

45. Zhou, Z.; Sun, L.; Zhao, Y.; An, L.; Yan, A.; Meng, X.; Gan, Y. Zinc Finger Protein 6 (ZFP6) regulates trichome initiation by integrating gibberellin and cytokinin signaling in Arabidopsis thaliana. New Phytol. 2013, 198, 699-708. [CrossRef]

46. Sun, L.; Zhang, A.; Zhou, Z.; Zhao, Y.; Yan, A.; Bao, S.J.; Yu, H.; Gan, Y. GLABROUS INFLORESCENCE STEMS3 (GIS3) regulates trichome initiation and development in Arabidopsis. New Phytol. 2015, 206, $220-230$. [CrossRef] 
47. Huang, L.; Jiang, Q.; Wu, J.; An, L.; Zhou, Z.; Wong, C.; Wu, M.; Yu, H.; Gan, Y. Zinc finger protein 5 (ZFP5) associates with ethylene signaling to regulate the phosphate and potassium defciency-induced root hair development in Arabidopsis. Plant Mol. Biol. 2020, 102, 143-158. [CrossRef]

48. Chang, J.; Yu, T.; Yang, Q.; Li, C.; Xiong, C.; Gao, S.; Xie, Q.; Zheng, F.; Li, H.; Tian, Z.; et al. Hair, encoding a single $\mathrm{C} 2 \mathrm{H} 2$ zinc-finger protein, regulates multicellular trichome formation in tomato. Plant J. 2018, 96, 90-102. [CrossRef]

49. Han, G.; Wei, X.; Dong, X.; Wang, C.; Sui, N.; Guo, J.; Yuan, F.; Gong, Z.; Li, X.; Zhang, Y.; et al. Arabidopsis ZINC FINGER PROTEIN1 Acts Downstream of GL2 to Repress Root Hair Initiation and Elongation by Directly Suppressing bHLH Genes. Plant Cell 2020, 32, 206-225. [CrossRef]

50. Tague, B.W.; Goodman, H.M. Characterization of a family of Arabidopsis zinc finger protein cDNAs. Plant Mol. Biol. 1995, 28, 267-279. [CrossRef]

51. Chrispeels, H.E.; Oettinger, H.; Janvier, N.; Tague, B.W. AtZFP1, encoding Arabidopsis thaliana C2H2 zinc-finger protein 1, is expressed downstream of photomorphogenic activation. Plant Mol. Biol. 2000, 42, 279-290. [CrossRef] [PubMed]

52. Clough, S.J.; Bent, A.F. Floral dip: A simplified method for Agrobacterium-mediated transformation of Arabidopsis thaliana. Plant J. 1998, 16, 735-743. [CrossRef] [PubMed]

53. Waterhouse, A.M.; Procter, J.B.; Martin, D.M.A.; Clamp, M.; Barton, G.J. Jalview Version 2-A multiple sequence alignment editor and analysis workbench. Bioinformatics 2009, 25, 1189-1191. [CrossRef] [PubMed]

54. Zhang, A.; Liu, D.; Hua, C.; Yan, A.; Liu, B.; Wu, M.; Liu, Y.; Huang, L.; Ali, I.; Gan, Y. The Arabidopsis gene zinc finger protein 3 (ZFP3) is involved in salt stress and osmatic stress responses. PLoS ONE 2016, 11, e0168367. [CrossRef] [PubMed]

55. Yan, A.; Wu, M.; Zhao, Y.; Zhang, A.; Liu, B.; Schiefelbein, J.; Gan, Y. Involvement of C2H2 zinc finger proteins in the regulation of epidermal cell fate determination in Arabidopsis. J. Integr. Plant Biol. 2014, 56, 1112-1117. [CrossRef]

56. Perazza, D.; Vachon, G.; Herzog, M. Gibberellins promote trichome formation by up-regulating GLABROUS1 in Arabiopsis. Plant Physiol. 1998, 117, 375-383. [CrossRef]

Publisher's Note: MDPI stays neutral with regard to jurisdictional claims in published maps and institutional affiliations.

(C) 2020 by the authors. Licensee MDPI, Basel, Switzerland. This article is an open access article distributed under the terms and conditions of the Creative Commons Attribution (CC BY) license (http://creativecommons.org/licenses/by/4.0/). 